\title{
Deposition and characterization of diamond-like nanocomposite coatings grown by plasma enhanced chemical vapour deposition over different substrate materials
}

\author{
AWADESH KR MALLIK ${ }^{\mathrm{a}, *}$, NANADADULAL DANDAPAT ${ }^{\mathrm{a}}$, PRAJIT GHOSH ${ }^{\mathrm{b}}$, \\ UTPAL GANGULY $^{\mathrm{b}}$, SUKHENDU JANA ${ }^{\mathrm{b}}$, SAYAN DAS ${ }^{\mathrm{b}}$, KAUSTAV GUHA ${ }^{\mathrm{c}}$, \\ GARFIELD REBELLO $^{\mathrm{d}}$, SAMIR KUMAR LAHIRI ${ }^{\mathrm{b}}$ and SOMESWAR DATTA ${ }^{\mathrm{a}}$ \\ ${ }^{a}$ Central Glass \& Ceramic Research Institute, CSIR, 196, Raja S. C. Mullick Road, Kolkata 700 032, India \\ ${ }^{b}$ Meghnad Saha Institute of Technology, Techno India Group, Kolkata 700 107, India \\ ${ }^{\mathrm{c}}$ Department of Chemistry, Durham University, Durham DH1 3LE, UK \\ ${ }^{\mathrm{d}}$ Perkin Elmer Technology Innovation Centre, Mumbai 400 059, India
}

MS received 2 August 2011; revised 2 September 2011

\begin{abstract}
Diamond-like nanocomposite (DLN) coatings have been deposited over different substrates used for biomedical applications by plasma-enhanced chemical vapour deposition (PECVD). DLN has an interconnecting network of amorphous hydrogenated carbon and quartz-like oxygenated silicon. Raman spectroscopy, Fourier transform-infra red (FT-IR) spectroscopy, transmission electron microscopy (TEM) and X-ray diffraction (XRD) have been used for structural characterization. Typical DLN growth rate is about $1 \mu \mathrm{m} / \mathrm{h}$, measured by stylus profilometer. Due to the presence of quartz-like $\mathrm{Si}: \mathrm{O}$ in the structure, it is found to have very good adhesive property with all the substrates. The adhesion strength found to be as high as $0.6 \mathrm{~N}$ on $\mathrm{SS} 316 \mathrm{~L}$ steel substrates by scratch testing method. The Young's modulus and hardness have found to be $132 \mathrm{GPa}$ and $14.4 \mathrm{GPa}$, respectively. DLN coatings have wear factor in the order of $1 \times 10^{-7} \mathrm{~mm}^{3} / \mathrm{N}-\mathrm{m}$. This coating has found to be compatible with all important biomedical substrate materials and has successfully been deposited over $\mathrm{Co}-\mathrm{Cr}$ alloy based knee implant of complex shape.
\end{abstract}

Keywords. Diamond-like carbon; plasma CVD; coatings; tribology.

\section{Introduction}

Protective coatings over steel and other metals, ceramics, glasses and polymers are deposited to increase the lifetime of different components for engineering applications. TiN, $\mathrm{CrN}$, AlTiN and different multilayer coatings are commercially available under different trade names. Apart from these nitride coatings, another method of enhancing the surface properties is to treat the engineering component under nitrogen plasma. Generally nitridation under definite surface bias potential penetrate the surface upto a certain depth (depending on the applied voltage and plasma treatment time) and thereby increase the surface hardness and corrosion resistance property of the metal component under engineering applications (Mukherjee et al 2004; Rao et al 2005). Carburisation is also a standard method of surface hardening. It is a heat treatment process in which iron or steel is heated in the presence of another material (in the range of 900$950^{\circ} \mathrm{C}$ ) which liberates carbon as it decomposes. Depending on the amount of time and temperature, varying amount of carbon diffuses into the part and the outer surface becomes

\footnotetext{
*Author for correspondence (amallik@cgcri.res.in)
}

hard via the transformation from austenite to martensite during quenching, while the core remains soft and tough as a ferritic and/or pearlite microstructure. Now other than these conventional methods of surface engineering (by nitridation or carburization), another class is carbon based coating material popularly termed as diamond-like carbon (DLC) coatings which have been in use for decades. But the main drawback of this type of coating is incompatibility with steel and other metals which has carbon solubility in the structure. There is a need of interlayer of chromium or titanium nitride before depositing DLC layer to prevent carbon diffusion into the substrate structure. Moreover the tribological performance of DLC reduces due to inherent stress inside the structure in the order of GPa. An unique class of material has been found which can be deposited over any substrate material with good tribological performance. This material is an interpenetrating network of amorphous hydrogenated carbon and quartz-like oxygenated silicon and is called diamond-like nanocomposite (DLN). Due to the presence of silicon in the structure, the adhesion to different substrates increases and internal stress reduction occurs.

DLN coatings have been in use since early 1990s. Dorfman (1992) first reported the synthesis of such unique class of material. Later on Bekaert advanced coating 
technologies (formerly known as advanced refractories technologies) and Russian and American scientists patented DLN coatings for various protective coating applications (Dorfman and Pypkin 1994, 1995; Emerson and Gu 1996; Dorfman and Goel 1998; Bosley and Miller 1998; Hooshang 2000; Neerinck and Goel 2001; Neerinck and Persoone 2001; Jacquet and Wietig 2006; Cooper et al 2007). DLN coatings are also used in micro-electromechanical systems (MEMS) applications like LIGA (German acronym for lithographie, galvanoformung und abformung) structures (Prasad et al 2003). Bekaert advanced coating technologies, Belgium have used plasma-enhanced chemical vapour deposition (PECVD) method for growing such composite films. Chinese researchers have successfully used ion beam technology for growing DLN films (Ding et al 1999). South Korean researchers have reported thermally activated CVD process for the growth of DLN films (Yang et al 2000). Moreover diamond-like carbon/nanosilica composite films have been deposited on silicon substrates, making use of the electrolysis of methanol-dimethylethoxydisilane (DDS) solution at low temperature (Yan et al 2004). In the present work, we have used PECVD with similar reactor used by Bekaert advanced coatings technology, Belgium. The reactor was available with one of our research collaborator, Meghnad Saha Institute of technology, Techno India group.

DLN have been characterized by various researchers (Pollak and Dorfman 1997; Polyakov et al 1997; Venkatraman et al 1997, 1999; Bozhko et al 1998; Dorfman 1998; Neerinck et al 1998a, b; Kester et al 1999; Platon et al 2001; Hauert and Muller 2003; Pandit and Padture 2003; Scharf and Singer 2003; Yang et al 2003a, b; Narayan 2005; Sheeja et al 2005; Kobayashi et al 2006; Maalouf et al 2006; Bursikova et al 2007; Logothetidis 2007; Scharf et al 2007). They have unique bulk and surface properties including an excellent thermal stability (Yang et al 2003a, b). The applications of DLN films include tribological coatings, chemical protective coatings (Neerinck et al 1998a, b; Kester et al 1999; Venkatraman et al 1999; Scharf and Singer 2003; Scharf et al 2007) and abrasion-resistant coatings for IR windows. They have unique control over optical properties and electrical properties (Polyakov et al
1997; Bozhko et al 1998; Dorfman 1998). Moreover it finds indirect application in the field of biomedical implants. Hydroxyapetite is widely used as plasma-sprayed coating for osteointegration of implants. DLN films have been reported to improve the adhesion of these coatings to the substrates (Narayan 2005). It has an excellent adhesion (Pandit and Padture 2003) to a variety of substrate materials due to a low residual stress, Moreover these films have found application as biosensors (Maalouf et al 2006). DLC coatings have been tried as protective wear resistant coating in joint prostheses (Platon et al 2001; Sheeja et al 2005). Diamondlike carbon (DLC) films were deposited onto UHMWPE and PMMA substrates using plasma CVD process (Kobayashi et al 2006). To improve adhesion of DLC films, substrates were plasma treated before DLC deposition. Carbonbased films have found to be haemobiocompatible as well (Logothetidis 2007). But so far there are not many literatures about DLN films in biomedical applications. Researchers at Department of Cardiology, University Hospitals Leuven, Belgium (De Scheerder et al 2000) have used either DLN (or Dylyn, Bekaert, Kortrijk, Belgium) coated or non-coated stents, randomly implanted in two coronary arteries of 20 pigs. The results indicate that the diamond-like nanocomposite stent coatings are compatible, resulting in decreased thrombogenicity and decreased neo-intimal hyperplasia. DLN coatings may have been in use commercially worldwide with different trade names, but there is no reported data available about its use in orthopedic applications. DLN films represent a significant advance over conventional diamondlike films in both stability and ability to tailor specific properties over a wide range. The properties are summarized in table 1 and compared with diamond and DLC coatings.

In the present study we have deposited DLN coatings by PECVD method over different substrates like, SS 316 L, glass, $\mathrm{Si}(100)$, ceramic $\left(\mathrm{Al}_{2} \mathrm{O}_{3}\right)$, ultra high molecular weight polyethylene (UHMWPE), Co-Cr alloy, Ti6Al4V alloy, etc. Most of these materials have been in use as load-bearing orthopedic implants, like hip joint, knee joint, etc (Rahaman et al 2007). Generation of UHMWPE wear particles is prime concern for failure of such implants. Many protective coatings like TiN, $\mathrm{CrN}$ (Ionbond $\AA$ coatings) or oxidized

Table 1. Comparison of properties among diamond, diamond-like carbon (DLC) and diamond-like nanocomposite (DLN) coatings.

\begin{tabular}{lccc}
\hline Properties & Diamond & DLC & DLN \\
\hline Resistivity $(\Omega \mathrm{cm})$ & $>10^{16}$ & $10^{10}-10^{13}$ & $10^{-4}-10^{14}$ \\
Hardness $(\mathrm{GPa})$ & 90 & $10-32$ & $10-22$ \\
Coefficient of friction (against steel) & - & $0 \cdot 1-0 \cdot 2$ & $0 \cdot 03-0 \cdot 2$ \\
Wear factor $\left(10^{-7} \mathrm{~mm}^{3} / \mathrm{Nm}\right)$ & - & $0 \cdot 5-1$ & $0 \cdot 2-0 \cdot 4$ \\
Transmission & $\mathrm{UV}-$ Vis-IR & Vis-IR & Vis-far IR \\
Modulus of elasticity $(\mathrm{GPa})$ & 1145 & $100-340$ & $150-200$ \\
Residual stress & Almost nil & $8-10 \mathrm{GPa}$ & $200-300 \mathrm{MPa}$ \\
Dielectric constant & - & - & $3-9$ \\
Maximum operating temperature $\left({ }^{\circ} \mathrm{C}\right)$ & - & 300 & $600\left(\mathrm{O}_{2}\right.$ atm $)$ \\
& & & $1200\left(\mathrm{O}_{2}\right.$ free $)$ \\
\hline
\end{tabular}


zirconium (oxinium, Smith \& Nephew $R$ ) have so far been used to reduce polyethylene wear of implants. But deposition of these coating materials involves high temperature processing of implant materials, which enhances the chances of loosing its mechanical property at high processing temperatures. DLN coating has been deposited at as low as $100{ }^{\circ} \mathrm{C}$, thereby enabling to coat even polymeric materials. So far DLN may not have been used as protective coating for biomedical applications. Although there are reports of DLC being used as protective coating in orthopedic implants (McNamara et al 2001; Platon et al 2001; Grill 2003; Hauert 2003; Hauert and Muller 2003; Sheeja et al 2005; Kobayashi et al 2006; Logothetidis 2007). Hauert (2003) in his review article, after describing contradicting results from various literatures has commented that the superior tribological properties of DLC in various environments can not probably be easily applied for hip joints and other load bearing implants as the build up of a transfer layer does not take place, and the UHMWPE counterpart still shows wear. According to Hauert (2003), DLC coated load bearing implants sliding against DLC coated counterparts or against ceramics may show good 'ceramic like' tribological properties, but he questioned of any real improvement in wear performance against the existing ceramic/ceramic or metal/ceramic bearings. Therefore, are attempt has been made to find an alternative DLN based protective coating, which does not have intrinsic stress and do not require interlayer to prevent carbon dissolution. Diamond-like nanocomposite coating is expected to enhance the tribological performance of orthopedic implants. Moreover DLN has been proven to be non-toxic. We hope that
DLN coating would be suitable material for biomedical tribology. The coating has been characterized by Raman spectroscopy, Fourier transform infrared spectroscopy (FT-IR), transmission electron microscopy (TEM), X-ray diffraction (XRD) for structural evaluation and mechanical properties like hardness and young's modulus have been tested. Thicknesses of the coatings have been calculated by stylus profilometer and growth rates were calculated from thickness measurements. Moreover tribological behaviour has been evaluated by ball-on-disc tribometer.

\section{Materials and methods}

\subsection{PECVD reactor}

One plasma-enhanced chemical vapour deposition (PECVD) reactor was used for deposition of DLN coatings as depicted in figure 1. This reactor had been in use for commercial production of Dylyn $(\mathbb{B}$ protective coatings. It had a rotating substrate holder at the top, which rotates at 2-3 rpm speed. There was a liquid precursor feeder at the bottom, through which liquid siloxane entered into the vacuum and due to the difference in pressure, evaporated into vapour form. There was one tungsten filament forming an arc above the liquid precursor feeder. This filament was negatively biased and there was an electron emission from the filament, which ionized the precursor vapour. These ionized precursor species was attracted by the substrate holder, which was again negatively biased at higher voltage. Before starting the precursor flow, argon

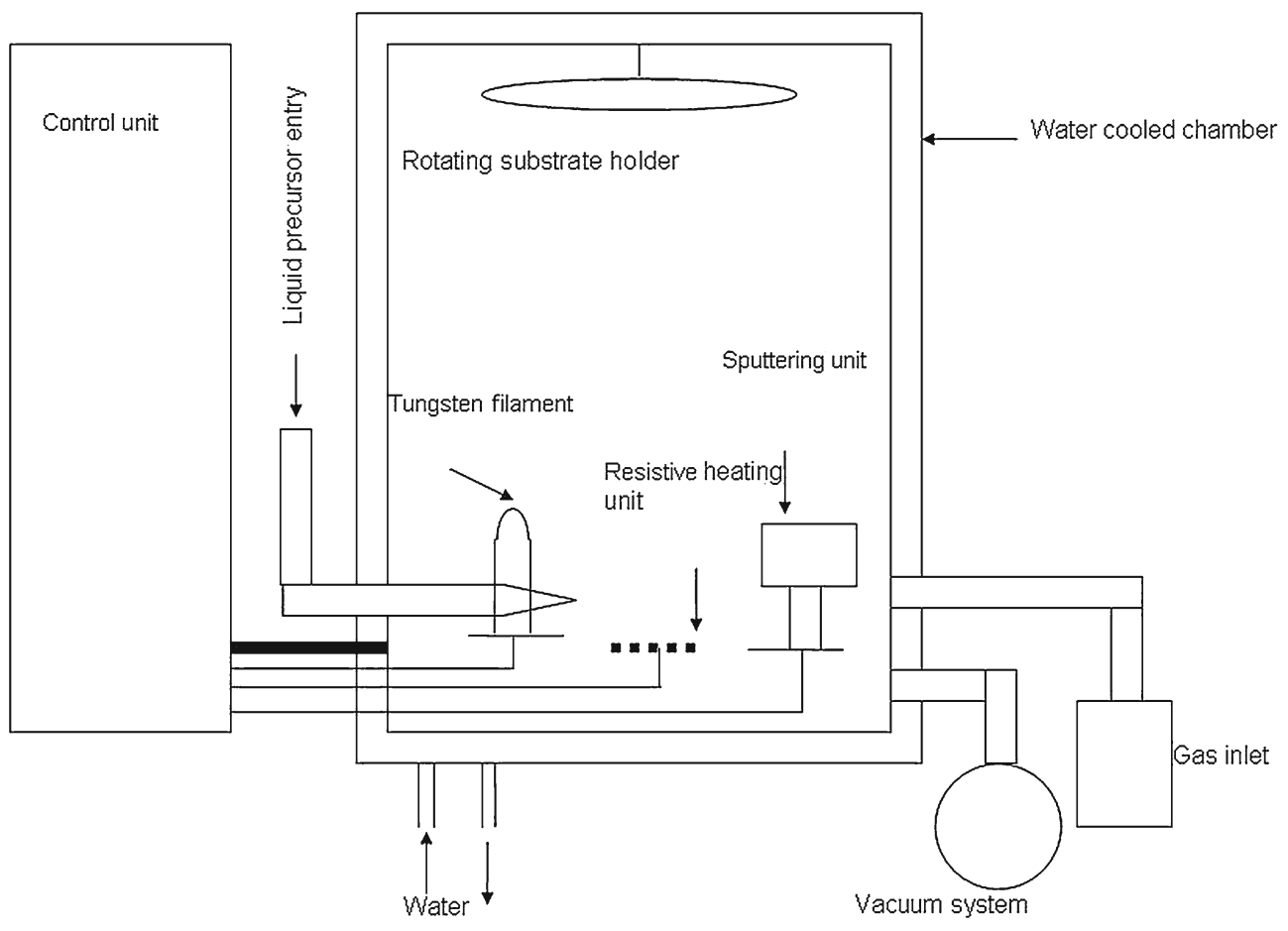

Figure 1. Schematic of PECVD reactor. 
gas was introduced into the reactor chamber to form plasma. Heavy argon ions bombarded the substrates and etched it to clean the substrates prior to deposition. There were provisions for resistive heating evaporation and sputtering of metal atoms for co-deposition inside this reactor. But during these set of experiments metal co-deposition was not done. The whole chamber was water cooled. There was a provision for substrate holder cooling as well. This is specially required for polymer substrates.

Deposition can be described in four steps: (a) plasma etching of the substrate by bombardment of the substrate by ions of an inert gas such as $\mathrm{Ar}$ (b) introducing a liquid organic precursor containing the elements $\mathrm{C}, \mathrm{H}, \mathrm{Si}$, O to be deposited in suitable proportions (remains substantially constant during the deposition process), in the vacuum chamber, at a working pressure between $5 \times 10^{-3}$ and $5 \times 10^{-2} \mathrm{mbar}$ (c) forming a plasma from the introduced precursor by an electron-assisted d.c.-discharge using a filament with a filament current of 50-150 A, a negative filament bias d.c. voltage of 50-300 V and with a plasma current between $0 \cdot 1$ and $20 \AA$ and (d) depositing the composition on the substrate, to which a negative d.c.-bias of 200 to $1200 \mathrm{~V}$ was applied, in order to attract ions formed in the plasma. Table 2 describes the substrates used during experiments and corresponding processing parameters.

\subsection{Physical characterizations}

Fourier-transform infrared spectroscopy (FT-IR) of the deposited films were done using Perkin Elmer Spectrum 100. Scan range was from $4000-650 \mathrm{~cm}^{-1}$. Source was MIR and detector was MIR TGS. Beamsplitter used was OptKBr and the instrument resolution was $4.00 \mathrm{~cm}^{-1}$. IR accessory type was Universal ATR and UATR. Crystal combination was diamond/ZnSe.

Raman spectroscopy was by far the best non-destructive way to study the bonding structure and quality of DLN films. The Raman microprobe studies were carried out in Durham University, UK. The Raman spectrometer was based on a commercial Raman microscope (Ramascope 1000, Renishaw) equipped with a $50 \times$ ULWD, 0.55 NA objective (Olympus). The DLN films were probed by a diode-pumped solid-state laser (Opus 532, Laser Quantum), which emitted light at the green region of spectrum at $532 \mathrm{~nm}$. The laser ( $5 \mathrm{~mW}$ intensity at source) beam was focussed to about $<2 \mu \mathrm{m}$ diameter spot and spectra were obtained with $5 \mathrm{~min}$ acquisition time.

Transmission electron microscopy (TEM) was done using model Tecnai $\mathrm{G}^{2} 30$ ST of FEI Company, Europe. X-ray diffraction patterns of the samples were recorded in X'pert Pro MPD diffractometer (PANanalytical) operating at $45 \mathrm{kV}$ and $35 \mathrm{~mA}$ using $\mathrm{Ni}$-filtered $\mathrm{CuK} \alpha$ radiation. XRD data were recorded in X'celerator from $10^{\circ}$ to $100^{\circ}$ with glancing angle thin film attachment. DLN coatings were seen under scanning electron microscope (LEO 430i STEROSCAN, UK) for microstructural evaluation of wear track along with EDAX analysis. Roughness was measured by surface profilometer (Surtronic 3p, Form Talysurf Plus, Rank Taylor Hobson Ltd, UK). Double-sided tape was used as masking material to form an uncoated portion on the substrate. Scanning of the coating, starting from coated portion to uncoated portion, produced a step in the roughness profile of the substrate. The height of the step was the thickness of the coating. If this thickness was divided by the deposition time of the coating, we get the growth rate of the plasma-enhanced chemical vapour deposition (PECVD).

\subsection{Mechanical characterization}

The microhardness on DLN coated steel and glass substrates was measured according to standard ASTM E2546 using Nanovea microhardness tester (MHT) at Micro Photonics Inc. The test conditions were as follows: Vickers diamond indenter, maximum force applied was $0.10 \mathrm{~N}$, loading rate was $0.20 \mathrm{~N} / \mathrm{min}$ and unloading rate was also $0.20 \mathrm{~N} / \mathrm{min}$. The values were computed using Oliver \& Pharr method.

Scratch resistance was measured by using sphero-conical stylus (Nanovea micro scratch tester of Micro Photonics Inc.) of $10 \mu \mathrm{m}$ radius with an initial load of $0.045 \mathrm{~N}$ and a final load of $2.0 \mathrm{~N}$ at loading rate of $2.0 \mathrm{~N} / \mathrm{min}$. Scratch length was $3 \mathrm{~mm}$ and scratching speed was $3.07 \mathrm{~mm} / \mathrm{min}$.

Wear and friction experiments were done on DLN-coated substrates with a ball on disc arrangement. Radius of the steel ball was $6.35 \mathrm{~mm}$ and a constant load of $1 \mathrm{~N}$ was applied while rotating in a $4 \mathrm{~mm}$ diameter circle at constant speed.

Table 2. PECVD deposition conditions.

\begin{tabular}{|c|c|c|c|c|c|c|}
\hline Substrates & $\begin{array}{c}\text { Precursor } \\
\text { flow rate } \\
(\mathrm{ml} / 10 \mathrm{~min})\end{array}$ & $\begin{array}{l}\text { Time of } \\
\text { deposition } \\
\text { (min) }\end{array}$ & $\begin{array}{c}\text { Total } \\
\text { precursor } \\
\text { used }(\mathrm{ml})\end{array}$ & $\begin{array}{c}\text { Bias } \\
\text { voltage } \\
\text { (V) }\end{array}$ & $\begin{array}{c}\text { Plasma } \\
\text { current } \\
(\AA)\end{array}$ & $\begin{array}{c}\text { Base } \\
\text { pressure } \\
\text { (mbar) }\end{array}$ \\
\hline SS 316L & 1.7522 & 100 & $19 \cdot 09$ & 550 & $0 \cdot 8$ & $1 \times 10^{-4}$ \\
\hline Ti6Al4V alloy and Co-Cr alloy & $1 \cdot 3831$ & 127 & $17 \cdot 57$ & 600 & $0 \cdot 8$ & $9.5 \times 10^{-5}$ \\
\hline UHMWPE and glass & 1.0199 & 29 & $2 \cdot 96$ & 600 & $0 \cdot 8$ & $9.6 \times 10^{-5}$ \\
\hline Acetabular cup & 0.8863 & 65 & $5 \cdot 761$ & 700 & $0 \cdot 8$ & $1 \times 10^{-4}$ \\
\hline Co-Cr alloy based knee implant & 1.6526 & 93 & $15 \cdot 371$ & 700 & $0 \cdot 8$ & $5 \times 10^{-5}$ \\
\hline
\end{tabular}




\section{Results and discussion}

\subsection{Physical properties}

Diamond-like nanocomposite is composite in nature at the molecular level. The chemical formulae of the siloxane precursor used for DLN synthesis composed of units of the form $R_{2} \mathrm{SiO}$, where $R$ is a hydrogen atom or a hydrocarbon group. A siloxane has a branched or unbranched backbone of alternating silicon and oxygen atoms $-\mathrm{Si}-\mathrm{O}-\mathrm{Si}-\mathrm{O}-$ with side chains $R$ attached to the silicon atoms. Here we have used triphenyl nona methyle penta siloxane precursor. Liquid precursor is bubbled into the vacuum inside the reactor, where it evaporates into the vapour form. These neutral molecules get ionized by electrons emitted thermionically from tungsten filament and form charged hydrocarbon and $\mathrm{SiO}$ species, which are being attracted towards the negatively biased substrate holder. DLN coating thus deposited is amorphous in nature and can be described as networks of amorphous hydrogeneted carbon and oxygeneted silicon entangled with each other.

Raman spectra of DLN films deposited on different substrates are shown in figure 2. The broad asymmetric bands

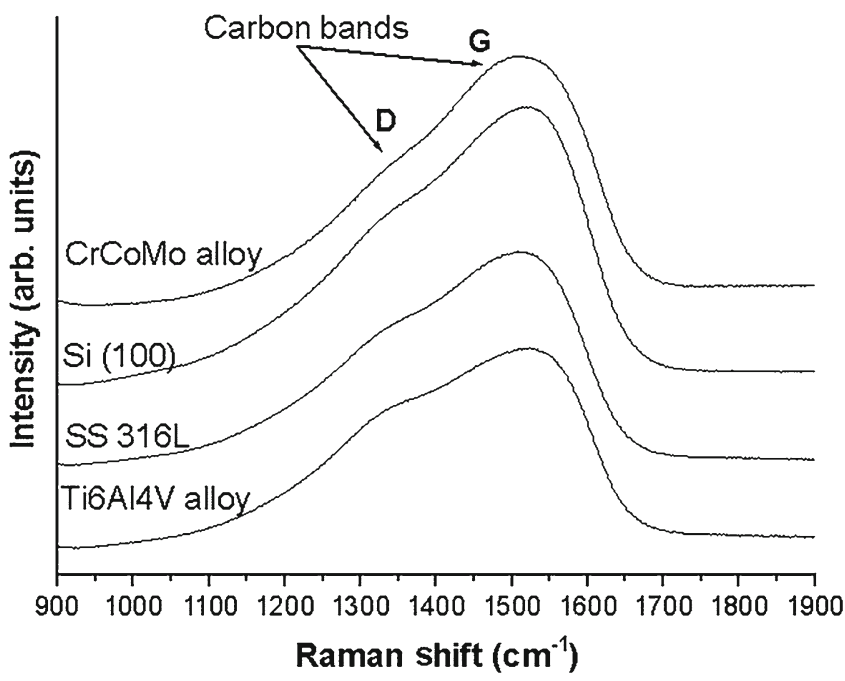

Figure 2. Raman spectra from DLN films coated on four different substrates: CrCoMo alloy, Si(100) wafer, SS 316 L, Ti6Al4V alloy (532 $\mathrm{nm}$ laser, $5 \mathrm{~mW}$ power, $5 \mathrm{~min}$ acquisition). in the $1000-1700 \mathrm{~cm}^{-1}$ are typical characteristics of amorphous carbon or diamond-like films (Yang et al 2003a, b). The Raman spectra were curve fitted to obtain a Gaussian deconvolution into $\mathrm{D}$ and $\mathrm{G}$ peaks as shown in table 3 . The $\mathrm{G}$ peak is a characteristic of single crystalline graphite, which results due to $E_{2 \mathrm{~g}} \mathrm{C}-\mathrm{C}$ stretching vibrations in the graphite layer and the $\mathrm{D}$ peak is a characteristic of disordered graphite, which results due to the $A_{1 \mathrm{~g}}$ vibrational modes (Robertson 2002). Hence $D$ stands for 'disorder' and $G$ stands for 'graphite'. In amorphous carbon films, the electronic properties are controlled by the $s p^{2}$ sites with $\pi$ bonds, and the mechanical properties are controlled by the $s p^{3}$ sites with $\sigma$ bonds (Robertson 1994).

Therefore, physical properties of DLN films can be explained by the $s p^{3} / s p^{2}$ ratio, which is correlated to the position and intensity ratio $\left(I_{\mathrm{D}} / I_{\mathrm{G}}\right)$ of the $\mathrm{D}$ and $\mathrm{G}$ peaks. The positional shift of the Raman $D$ and $G$ peaks can reflect the difference in actual film structures (Yang et al 2003a, b); however, the peaks can also be a little shifted due to the difference in light source of the Raman spectrometer, curve fitting parameters applied and so on. In table 3, the comparison shows that the $I_{\mathrm{D}} / I_{\mathrm{G}}$ ratio in the Raman spectra of DLN films coated on different substrates have gradually increased from 1.53 for $\mathrm{CrCoMo}$ alloy to 2.71 for $\mathrm{Ti}_{6} \mathrm{Al}_{4} \mathrm{~V}$ alloy. This increase in $I_{\mathrm{D}} / I_{\mathrm{G}}$ ratio is associated with a relative increase in the $s p^{3}$ site content (or a relative decrease in the $\mathrm{sp}^{2}$ site content) in the respective DLN films. It is regarded that a higher graphite (or $s p^{2}$ ) content in the amorphous carbon films reduces the hardness of the films. Therefore we can predict to observe an increasing order of hardness in the DLN films with an increasing value of $I_{\mathrm{D}} / I_{\mathrm{G}}$ ratio.

Figure 3 shows FT-IR spectra of DLN films on stainless steel and glass substrates. Major absorption band of the $\mathrm{Si}-\mathrm{O}$ stretching in the $1100-1000 \mathrm{~cm}^{-1}$ range is observed in both the FT-IR spectra of DLN films. Second prominent absorption band we could find in the $3100-2800 \mathrm{~cm}^{-1}$ range, was of the $\mathrm{C}-\mathrm{H}$ stretching. The $\mathrm{C}-\mathrm{H}$ absorption band in the $3100-$ $2800 \mathrm{~cm}^{-1}$ range is typical for $s p^{3}$ - and $s p^{2}$-bonded carbon. These $\mathrm{C}-\mathrm{H}$ and $\mathrm{Si}-\mathrm{O}$ stretching peaks prove that DLN films mainly consist of hydrogenated carbon $(\mathrm{C}: \mathrm{H})$ and oxygenated silicon $(\mathrm{Si}: \mathrm{O})$ networks. Apart from the interpenetrating networks of $\mathrm{Si}: \mathrm{O}$ and $\mathrm{C}: \mathrm{H}$, there were also the presence of non-graphitic carbon and $\mathrm{Si}-\mathrm{C}$ like bondings. There is a small hump of $\mathrm{Si}-\mathrm{C}$ stretching in the $800 \mathrm{~cm}^{-1}$ region. Presence of non-graphitic bonding of carbon is confirmed by

Table 3. Gaussian analyses of Raman spectra deconvoluted into D and G peaks in DLN films coated in different substrates ( $\nu$ : position, $\Gamma$ : full width at half maxima and $I$ : integrated intensity).

\begin{tabular}{|c|c|c|c|c|c|}
\hline Substrates & $v_{\mathrm{D}}\left(\mathrm{cm}^{-1}\right)$ & $\Gamma_{\mathrm{D}}\left(\mathrm{cm}^{-1}\right)$ & $v_{\mathrm{G}}\left(\mathrm{cm}^{-1}\right)$ & $\Gamma_{\mathrm{G}}\left(\mathrm{cm}^{-1}\right)$ & $I_{\mathrm{D}} / I_{\mathrm{G}}$ \\
\hline CrCoMo alloy & $1396 \cdot 4$ & 272.733 & $1536 \cdot 91$ & $156 \cdot 493$ & 1.53 \\
\hline $\operatorname{Si}(100)$ & $1385 \cdot 5$ & $305 \cdot 251$ & 1533.94 & $146 \cdot 974$ & $2 \cdot 05$ \\
\hline SS $316 \mathrm{~L}$ & 1382.9 & $300 \cdot 112$ & 1529.08 & $145 \cdot 306$ & $2 \cdot 19$ \\
\hline $\mathrm{Ti}_{6} \mathrm{Al}_{4} \mathrm{~V}$ alloy & $1390 \cdot 78$ & $304 \cdot 394$ & 1541.07 & $138 \cdot 599$ & $2 \cdot 71$ \\
\hline
\end{tabular}





Figure 3. FT-IR spectra of DLN films deposited on SS $316 \mathrm{~L}$ and glass substrates.

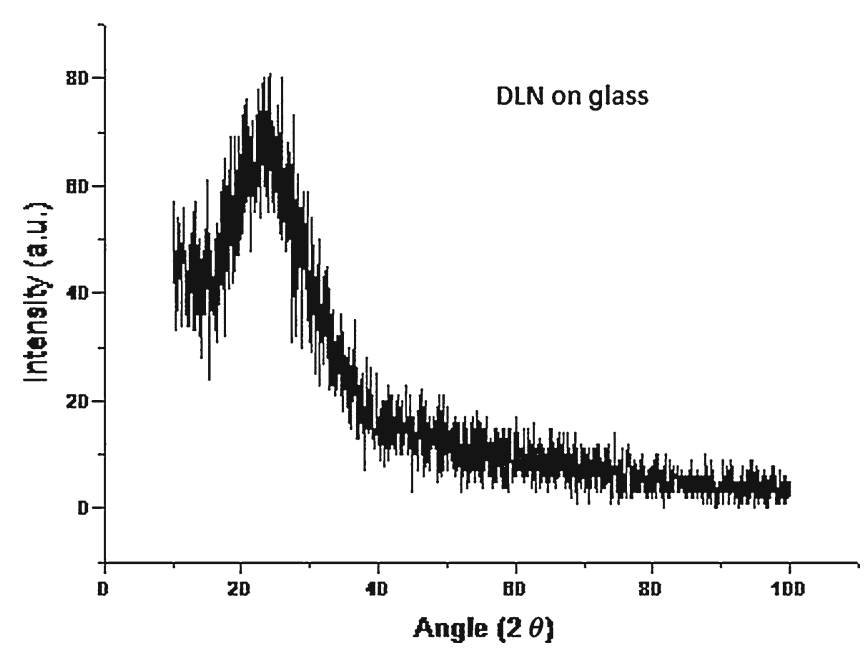

Figure 4. XRD micrograph of DLN deposited on glass showing amorphous nature of deposited film.

$\mathrm{C}=\mathrm{C}$ stretching peaks appearing in the $1580 \mathrm{~cm}^{-1}$ region. Also we could see $\mathrm{Si}-\mathrm{H}$ stretching appearing in $2100 \mathrm{~cm}^{-1}$ region. Our results exactly match with reported literature values (Yang et al 2003a, b). Chemical composition was also studied using an EDAX of the worn films.

Figure 4 indicates that XRD could not detect any crystallinity within its resolution. XRD patterns were taken from DLN coatings on glass substrates. The hump around $2 \theta=$ $26.5^{\circ}$ in the scan is typical for amorphous films grown on quartz microscope slides, due to the presence of $\mathrm{SiO}_{2}$ in the bottom glassy substrate. To further prove the amorphous nature of the film, transmission electron microscopy was done on DLN coatings. DLN deposited onto $50 \mu \mathrm{m}$ thick aluminum foil has been plasma-etched from the opposite uncoated side of the foil, so as not to damage the DLN coating. Once one hole has been created in the foil, DLN film was

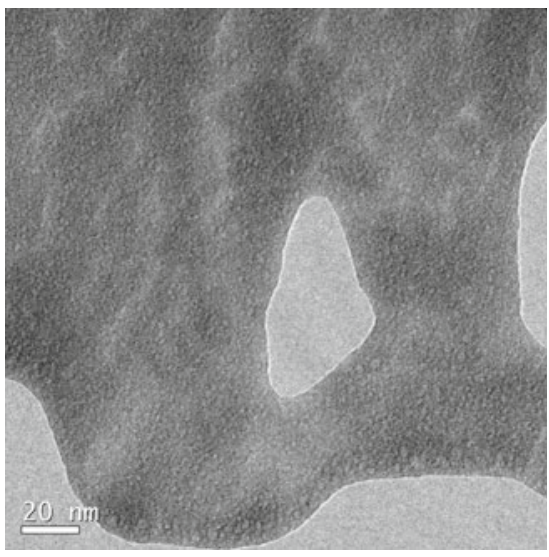

Figure 5. TEM micrograph around plasma-etched hole.

seen in and around the created hole under transmission electron microscope. Figure 5 shows typical TEM micrographs, which are characteristics of amorphous structure (Yang et al 2003a, b).

The average $R_{\mathrm{a}}$, roughness of the bare steel substrates before deposition was found to be $0 \cdot 1 \mu \mathrm{m}$. DLN coatings follow the contours of the underlying substrate. The $R_{\mathrm{a}}$, roughness does not vary much after deposition. It is found to be $0.15 \mu \mathrm{m}$. Roughness of DLN films deposited on laboratory glass slide substrates was beyond instrument range as it followed the very smooth surface of glass slides. The advantage of this is that there is no need of post-deposition polishing of DLN coating on well polished substrates. Any other wear resistance protective coating has to be polished to reduce the surface roughness prior to application. Upper scan profile of figure 6 shows a $1.75 \mu \mathrm{m}$ step in the profilometer scan of the substrate for DLN on SS $316 \mathrm{~L}$ combination. The coating had been grown for $100 \mathrm{~min}$, thus the growth rate was calculated to be $1.04 \mu \mathrm{m} / \mathrm{h}$. Bottom scan profile of figure 6 shows one 

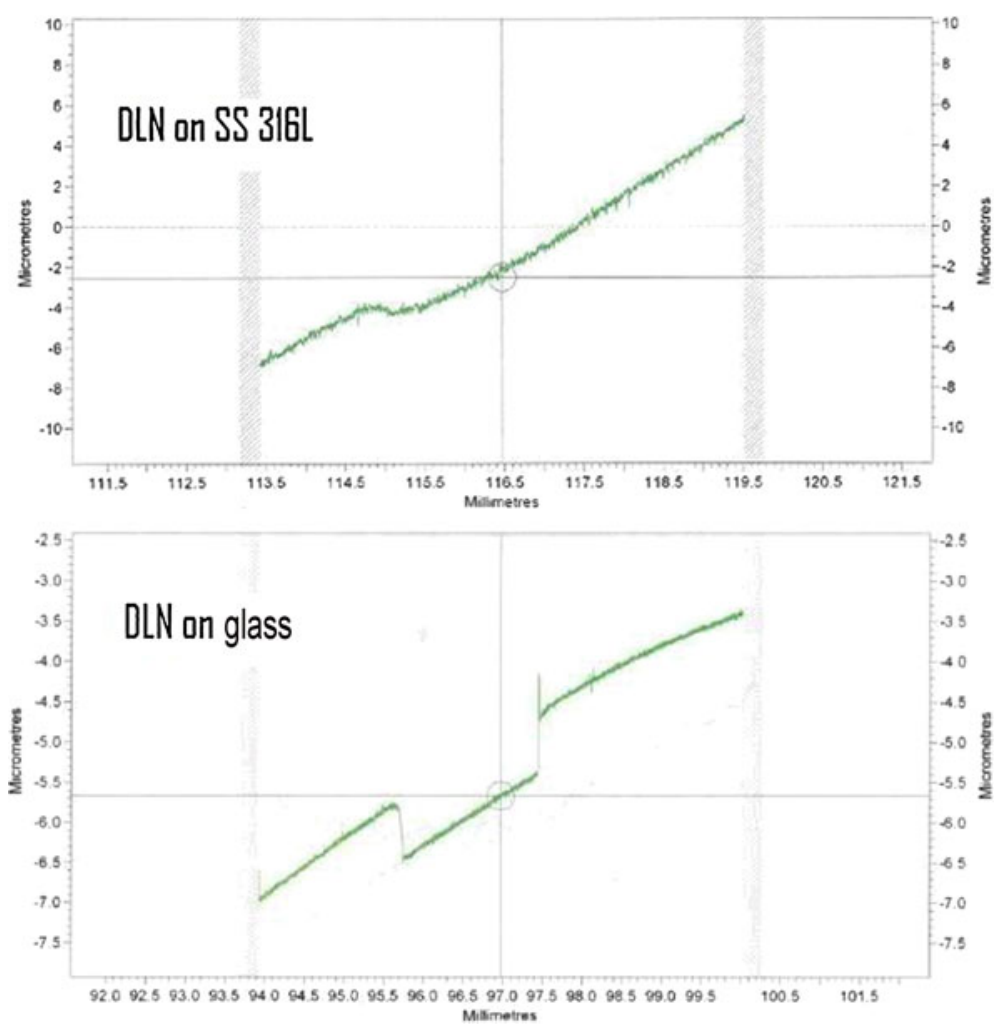

Figure 6. Typical profilometer scan of DLN coating for thickness measurement: (a) SS $316 \mathrm{~L}$ substrate and (b) glass substrate.
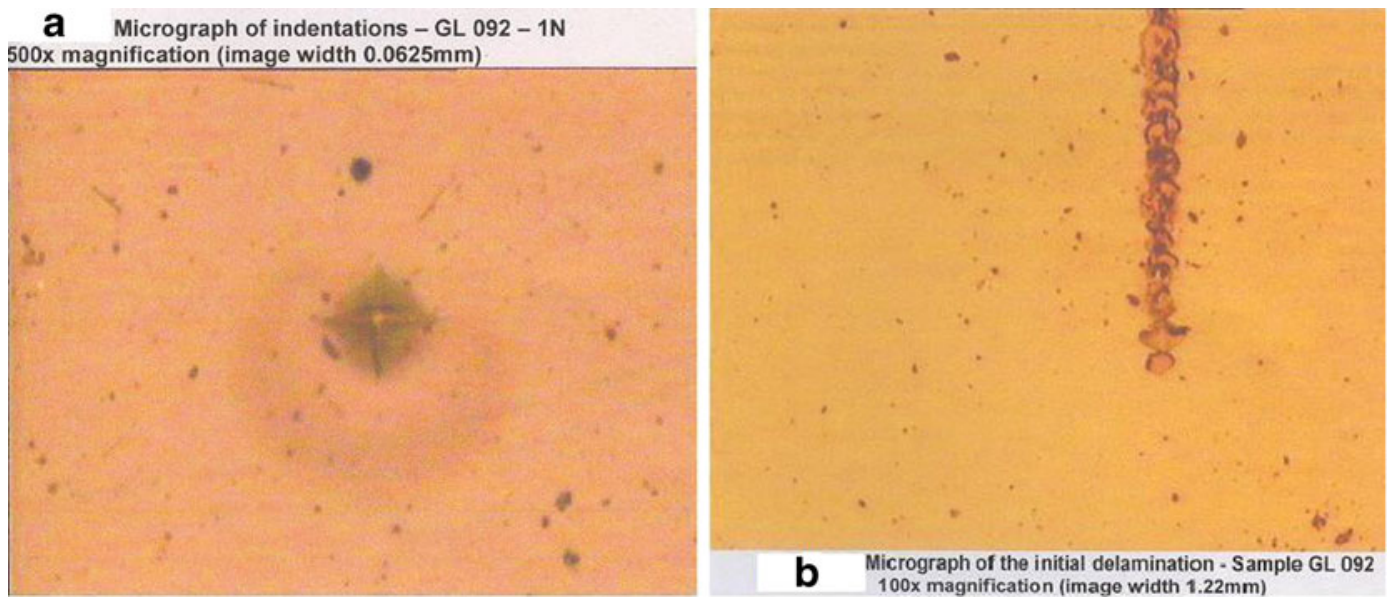

Figure 7. Optical micrographs of (a) microindentation mark on DLN-coated glass substrate and (b) scratch resistance test mark on DLN-coated glass sample.

Table 4. Mechanical properties of DLN coatings.

\begin{tabular}{|c|c|c|c|c|c|}
\hline Sample & $\begin{array}{l}\text { Roughness, } \\
\quad R_{\mathrm{a}}(\mu \mathrm{m})\end{array}$ & $\begin{array}{l}\text { Thickness } \\
(\mu \mathrm{m})\end{array}$ & $\begin{array}{l}\text { Hardness } \\
(\mathrm{GPa})\end{array}$ & $\begin{array}{c}\text { Young's } \\
\text { modulus (GPa) }\end{array}$ & $\begin{array}{c}\text { Critical load } L_{\mathrm{C}}(\mathrm{N}) \\
\text { with standard deviation }\end{array}$ \\
\hline $\begin{array}{l}\text { DLN on SS } 316 \mathrm{~L} \\
\text { substrates }\end{array}$ & $\begin{array}{l}0.1003 \text { (bare) } \\
0 \cdot 1466(\text { coated })\end{array}$ & 1.75 & 17 & 132 & $0 \cdot 618 \pm 0 \cdot 004$ \\
\hline $\begin{array}{l}\text { DLN on glass } \\
\text { substrates }\end{array}$ & $\begin{array}{l}\text { Very smooth before } \\
\text { and after coating }\end{array}$ & $0 \cdot 66$ & 14 & 73 & $0 \cdot 196 \pm 0.023$ \\
\hline
\end{tabular}


Table 5. Wear and friction data of steel ball sliding against DLNcoated silicon substrate.

\begin{tabular}{lccc}
\hline $\begin{array}{l}\text { Temperature } \\
\left({ }^{\circ} \mathrm{C}\right)\end{array}$ & $\begin{array}{c}\text { No. of } \\
\text { revolutions }\end{array}$ & $\begin{array}{c}\text { Wear } \\
\left(\mathrm{mm}^{3} / \mathrm{N}-\mathrm{m}\right)\end{array}$ & $\begin{array}{c}\text { Coefficient } \\
\text { of friction }\end{array}$ \\
\hline 28.8 & 90000 & $1.26 \mathrm{E}-7$ & 0.043 \\
30.4 & 110000 & $1.33 \mathrm{E}-7$ & 0.092 \\
28.4 & 150000 & $1.79 \mathrm{E}-7$ & 0.143 \\
\hline
\end{tabular}

trough in the scan profile of DLN on glass slide, as the stylus moves from coated portion through uncoated portion to other side of the coated portion of the substrate. The thickness was found to be $660 \mathrm{~nm}$. Deposition time was $29 \mathrm{~min}$ (table 2). So the growth rate was calculated to be $1.365 \mu \mathrm{m} / \mathrm{h}$. It has been found that typical growth rate varies between 1 and $3 \mu \mathrm{m} / \mathrm{h}$.

\subsection{Mechanical properties and tribology}

Mechanical properties along with roughness values of DLN coatings on steel and glass substrates have been tabulated in table 4 . Indentation with $0.1 \mathrm{~N}$ load was not clearly visible, so tests were performed with $1 \mathrm{~N}$ and $3 \mathrm{~N}$ loads. Figure 7(a) shows micro-indentation mark on DLN coating. It is found that DLN deposited on stainless steel has higher hardness value of $17 \mathrm{GPa}$ in comparison to hardness value of 14 GPa of DLN coatings deposited on glass substrates. Not only the hardness values are higher for steel substrates but also Young's modulus for steel substrates is $132 \mathrm{GPa}$ when compared to $73 \mathrm{GPa}$ for glass substrates. The literature values of hardness for this class of materials vary between 12 and $17 \mathrm{GPa}$ (Bozhko et al 1998), which is in complete agreement with present findings. Now, whereas plasma immersion ion implantation (PIII) techniques could give only 8-9 GPa of surface hardness of AISI $304 \mathrm{~L}$ stainless steel (Rao et al 2005).

Scratch resistance has been reported by critical force, $L_{\mathrm{C}}$, at which damage of the coating occurs. The critical load is optically defined by the point where the substrate is completely uncovered in the scratch track for a length equal or greater than the scratch width. The optical micrograph in figure 7(b) shows typical scratch track. At least five measurements were done on each sample to calculate the average $L_{\mathrm{C}}$. The critical load $L_{\mathrm{C}}$ for DLN coatings on steel substrates was found to be $0.618 \mathrm{~N}$ and the $L_{\mathrm{C}}$ for DLN coatings on glass substrates was found to be $0 \cdot 196 \mathrm{~N}$. With such good adhesive strength and hardness values, DLN could find wide application as wear-resistant coating.

Sliding wear behaviour of steel ball sliding against DLN coating under dry conditions is shown in table 5 . The experiments were conducted under room temperature conditions. Steel ball was made to revolve in $4 \mathrm{~mm}$ diameter circle on DLN-coated substrates. The steady state coefficient of friction (COF) changes from 0.043 to 0.092 when revolution changes from 90000 to 110000 . The corresponding calculated wear factors are $1.26 \times 10^{-7} \mathrm{~mm}^{3} / \mathrm{N}-\mathrm{m}$ and $1.33 \times$ $10^{-7} \mathrm{~mm}^{3} / \mathrm{N}-\mathrm{m}$, respectively. Obviously, the wear volume will increase if the ball is made to revolve for higher number of revolutions of 150000 , but in that case the average COF strikingly increases to $0 \cdot 143$, much higher than 90000 and



Figure 8. Portion of wear track of DLN film with EDAX analysis from wear groove and unworn surface. 


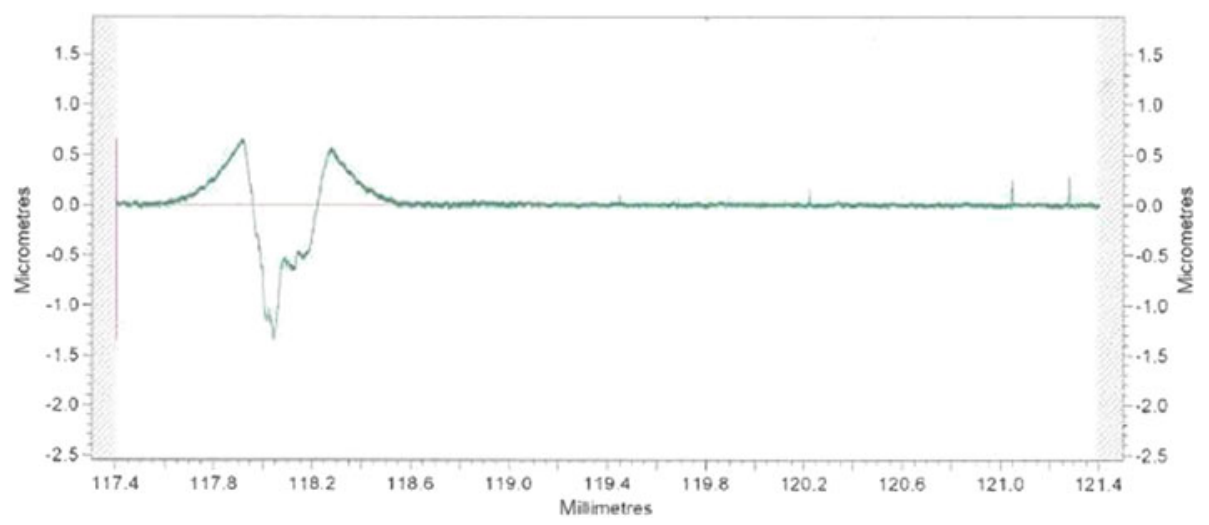

Figure 9. Profilometer scan across wear track.

110000 revolutions. Whereas the reported literature COF values for such wear experiments have always been below 0.1 (Neerinck et al 1998a, b). This anomaly in COF values between reported and available literature may be due to the fact that, as the ball is made to slide for longer duration, the underneath substrate comes out due to wearing of DLN coating and thus the resultant values of friction correspond to the values between steel ball sliding against bare $\mathrm{Si}$ substrate. This is evident from the SEM images of figure 8, where bare silicon substrate is visible due to wearing out of DLN coating. Moreover the EDAX from whitish portion of the wear groove indicates presence of $\mathrm{Fe}, \mathrm{Co}, \mathrm{Ni}$ and $\mathrm{O}$ which is typical of the steel ball composition. Thus there is a clear evidence of material transfer between ball and coated substrate. Figure 9 shows profilometer scan of the wear groove. The depth of the groove shows $1.5 \mu \mathrm{m}$ whereas the coating thickness was $<1 \mu \mathrm{m}$. This difference between coating thickness and wear track depth further confirms exposure of the underneath silicon substrate.

\section{Conclusions}

\subsection{PECVD}

(I) DLN has been successfully deposited on many types of substrates, including polymers, glass, ceramics and metals (including aluminum, stainless steel and silicon) by PECVD. (II) There was no need for interlayer prior to DLN deposition on all substrates.

(III) Large area deposition $\left(\sim 3000 \mathrm{~cm}^{2}\right)$ has been achieved in PECVD reactor.

\subsection{DLN coating}

(I) DLN films mainly consist of hydrogenated carbon (C:H) and oxygenated silicon ( $\mathrm{Si}: \mathrm{O})$ networks, as evident from FT-IR spectra.

(II) Presence of $s p^{3}$ carbon and $s p^{2}$ graphite inside the structure is evident from Raman spectroscopy.

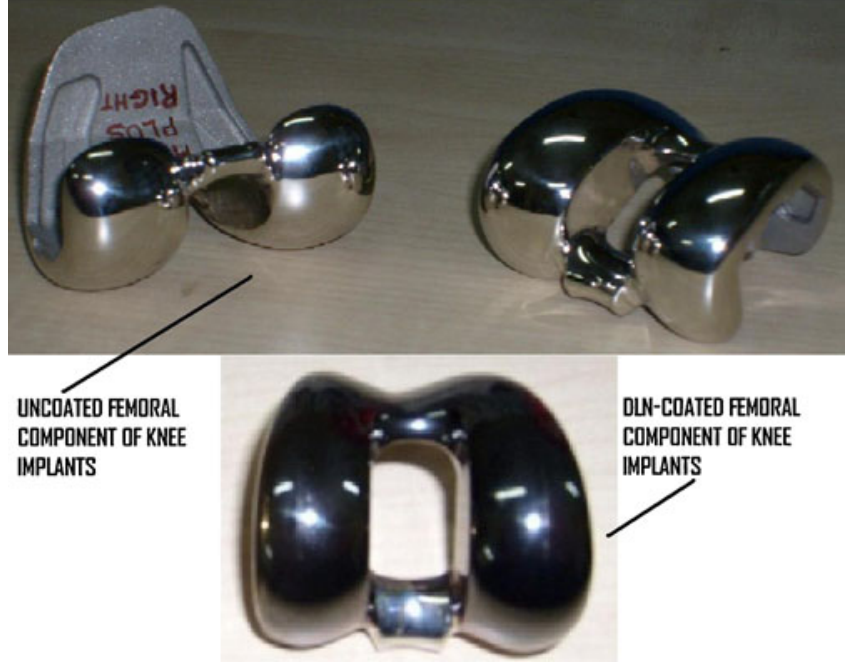

Figure 10. Femoral components of knee implant: (a) uncoated Co-Cr based alloy and (b) DLN-coated.

(III) Films are not only X-ray amorphous but also it is nanocomposite in nature under TEM micrograph.

\subsection{Mechanical properties}

(I) DLN coatings follow the contours of the underlying substrate with the advantage of non-requirement of postdeposition polishing of well-polished parts.

(II) Substantial enhancement of the surface hardness is achieved with DLN coating.

(III) Adhesion strength is better with metallic substrates than glass substrates which is essential for adhesive wear applications like hip joints and knee joints.

(IV) After depositing over different materials of biomedical importance, we have successfully deposited DLN coating on femoral components of $\mathrm{Co}-\mathrm{Cr}$ alloy-based knee implants of complex shape as shown in figure 10. With such good mechanical performance DLN is a potential coating for biomedical tribology. 


\section{Acknowledgements}

We express our sincere gratitude to Dr K H Sancheti for allowing us to coat indigenously developed 'Indus Knee' orthopedic implant. Dr Raghu Bhattacharyya helped in solving many technical problems through discussions. Soumya Sarkar has done the profilometer measurements. Dr Sandip Bysakh kindly did the TEM measurements. Authors also thank Dr (Mrs) S Sen and Mrs S Roy for their help in taking SEM micrographs. We are thankful to Dr S Majumdar for allowing us to do XRD measurements. Mr. Guillaume Begin of Micro Photonics Inc. and Mr. Rajkishore Sahani of Material Testing \& Metallurgy Group, Aimil Ltd., Kolkata, have done hardness and scratch resistence testing of DLN coatings. We are grateful to Prof. Colin Bain for allowing us to use Raman facility.

\section{References}

Bosley R W and Miller R F 1998 United States Patent 5827040

Bozhko A, Chudinov S M, Evangelisti M, Stizza S and Dorfman V F 1998 Mater. Sci. Eng. C5 265

Bursikova V, Rehulkab P, Chmelikb J, Albertia M, Spaltc Z, Jancaa J and Havel J 2007 J. Phys. Chem. Solids 68701

Cooper C V, Tredway W K, Guile R N, Rhemer C C, Minick A B and Chapman L W 2007 Cryogenic bearings, United States Patent 7296965

De Scheerder I, Szilard M, Yanming H, Ping X B, Verbeken E, Neerinck D, Demeyere E, Coppens W and Van de Werf F 2000 J. Invasive Cardiol. 12389

Ding X-Z, Zhang F-M, Liu X-H, Wang P W, Durrer W G, Cheung W Y, Wang S P and Wilson I H 1999 Thin Solid Films 34682

Dorfman V F 1998 Thin Solid Films 33076

Dorfman V F 1992 Thin Solid Films 212267

Dorfman V F and Goel A 1998 United States Patent 5728465

Dorfman V F and Pypkin B 1994 United States Patent 5352493

Dorfman V F and Pypkin B 1995 United States Patent 5466431

Emerson T P and Gu A L 1996 United States Patent 5529464

Grill A 2003 Diam. Relat. Mater. 12166

Hauert R and Muller U 2003 Diam. Relat. Mater. 12171

Hauert R 2003 Diam. Relat. Mater. 12583

Hooshang H 2000 United States Patent 6158893

Jacquet J M and Wietig F G 2006 Patent number WO 2006/125683

Kester D J, Brodbeck C L, Singer I L and Kyriakopoulos A 1999 Surf. Coat. Technol. 113268
Kobayashi S, Ozeki K, Hirakuri K K and Aoki H 2006 Key Eng. Mater. 309-311 1289

Logothetidis S 2007 Diam. Relat. Mater. 161847

Maalouf R, Jaffrezic-Renault N, Vittori O, Sigaud M, Saikali Y, Chebib H, Loir A S, Garrelie F, Donnet C, Takeno T and Takagi T 2006 J. Adv. Sci. 1831

McNamara B P, Murphy H and Morshed M M 2001 Diam. Relat. Mater. 101098

Mukherjee S, Raole P M, Kumar A, Chattoraj I, Rao K R M and Manna I 2004 Surf. Coat. Technol. 186282

Narayan R J 2005 Mater. Sci. Eng. C25 398

Neerinck D, Persoone P, Sercu M, Goel A, Kester D and Bray D 1998a Diam. Relat. Mater. 7468

Neerinck D, Persoone P, Sercu M, Goel A, Venkatraman C, Kester D, Halter C, Swab P and Bray D 1998b Thin Solid Films 317402 Neerinck D and Goel A 2001 United States Patent 6200675

Neerinck D and Persoone P 2001 United States Patent 6228471

Pandit A and Padture N P 2003 J. Mat. Sci. Lett. 221261

Platon F, Fournier P and Rouxel S 2001 Wear 250227

Pollak F H and Dorfman B 1997 Thin Solid Films 292173

Polyakov V I, Rukovishnikov A I, Perov P I, Khomich A V, Sukhanov A A, Dorfman B F, Pypkin B N, Abraizov M G and Druz B 1997 Thin Solid Films 29291

Prasad S V, Christenson T R, Dugger M T, Michael J R and Vanecek C W 2003 American Society for Precision Engineering, Winter Topical Meeting, Vol. 28

Rahaman M N, Yao A, Bal B S, Garino J P and Ries M D 2007 J. Am. Ceram. Soc. 901965

Rao K R M, Mukherjee S, Raole P M and Manna I 2005 Surf. Coat. Technol. 2002049

Robertson J 1994 Pure Appl. Chem. 661789

Robertson J 2002 Mater. Sci. Eng. R37 129

Scharf T W and Singer I L 2003 Tribol. Lett. 143

Scharf T W, Ohlhausen J A, Tallant D R and Prasad S V 2007 J. Appl. Phys. 1010635211

Sheeja D, Tay B K, Nung L N 2005 Surf. Coat. Technol. 190231

Venkatraman C, Brodbeck C and Lei R 1999 Surf. Coat. Technol. 115215

Venkatraman C, Goel A, Lei R, Kester D and Outten C 1997 Thin Solid Films 308-309 173

Yan X-B, Xu T, Chen G, Xue Q-J and Yang S-R 2004 Electrochem. Commun. 61159

Yang W J, Auh K H, Li C and Niihara K 2000 J. Mat. Sci. Lett. 19 1649

Yang W J, Choab Y-H, Sekinoc T, Shima K B, Niiharac K and Auha K H 2003a Mater. Lett. 573305

Yang W J, Choab Y-H, Sekinoc T, Shima K B, Niiharac K and Auha K H 2003b Thin Solid Films 43449 